\title{
DE HITLER À LULA: ANÁLISE SOBRE A IMAGEM E SEUS EFEITOS DE SENTIDO NO DISCURSO PUBLICITÁRIO DA FOLHA DE SÃO PAULO
}

\author{
FROM HITLER TO LULA: ANALYSIS ON THE IMAGE AND ITS SENSE \\ EFFECTS IN THE ADVERTISING DISCOURSE OF FOLHA DE SÃO PAULO
}

\author{
Edjane Gomes de Assis \\ Universidade Federal da Paraíba \\ UFPB/ João Pessoa \\ assisedjane@hotmail.com
}

\begin{abstract}
RESUMO: "Obrigar-se a ponderar da parte acusada e, publicando uma acusação, garantir espaço ao contraditório". (FOLHA DE SÃO PAULO, 2018). Estes são alguns dos princípios prescritos no Manual de redação da Folha de São Paulo - versão reformulada e publicada em 2018. Entendemos que todo dizer é constituído por elementos sociais, históricos e ideológicos, e a mídia se subjetiviza como um lugar de verdade, terreno fértil para o plantio de valores e imagens sobre os sujeitos, sobretudo quando tais sujeitos ocupam lugares de destaque na história, à exemplo de Adolf Hitler e Luís Inácio Lula da Silva. Duas figuras antagônicas por suas atitudes, mas emblemáticas pela posição de liderança política que ocuparam/ocupam na história. Com base nestas premissas pautadas na Análise do discurso foucaultiana e mantendo um diálogo com os estudos da Semiótica greimasiana, nosso trabalho tem por objetivo analisar duas propagandas da Folha de São Paulo em que são utilizadas as imagens de Hitler e Lula para validar o dizer do periódico. Vinculadas em momentos distintos (a propaganda com Hitler exibida em 1987 e com Lula, exibida em 2018), a Folha se utiliza de estratégias e dispositivos de controle, ao fazer voltar o acontecimento para ratificar seu compromisso com a ética e a imparcialidade da informação. Os recursos tecnológicos utilizados por meio de diversas semioses, disciplinam o olhar do leitor ao projetar, de modo gradativo, o rosto dos dois líderes como um quebra-cabeça cujas peças promovem um verdadeiro espetáculo de olhares. Entendemos que, mediante o devir da memória (utilização da imagem de Hitler para dialogar com a imagem de Lula), a Folha se subjetiviza estabelecendo jogos de similitudes entre o passado e o presente. Mesmo "primando" pelo discurso da verdade, o periódico deixa marcas de uma memória que tenta apagar/silenciar - o apoio à ditadura militar do Brasil, bem como sua posição contrária aos partidos de esquerda.
\end{abstract}

Palavras-chave: Discurso; Folha de São Paulo; Sentidos.

ABSTRACT: "Forcing to consider the accused party and, publishing an accusation, guarantee space to the contradictory". (FOLHA DE SÃO PAULO, 2018). These are some of the principles prescribed in the Folha de São Paulo Writing Manual - a recast version published in 2018. We understand that all say is constituted by social, historical and ideological elements, and the media is subjected as a place of truth, fertile ground for planting values and images on subjects, especially when such subjects occupy prominent places in history, like Adolf Hitler and Luís Inácio Lula da Silva. Two antagonistic figures for their attitudes, but emblematic for the position of political leadership they occupied/occupy in history. Based on these premises based on the Analysis of Foucaultian discourse and maintaining a dialogue with the studies of the Semiotics of The Greimasian Semiotics, our work aims to analyze two advertisements of Folha de São Paulo in which the images of Hitler and Lula are used to validate the journal's say. Linked at different moments (propaganda with Hitler exhibited in 1987 and lula, exhibited in 2018), Folha uses strategies and control devices, in returning the event to ratify its commitment to the ethics and impartiality of the Information. The technological resources used through several semioses discipline the reader's gaze by gradually designing the face of the two leaders as a puzzle whose pieces promote a true spectacle of looks. We understand that, through the coming of memory (use of Hitler's image to dialogue with Lula's image), Folha is subjected by establishing games of similitudes between the past and the present. Even "excelling" by the discourse of truth, the journal leaves marks of a memory that tries to erase/silence - support for Brazil's military dictatorship, as well as its position contrary to leftist parties.

Keywords: Speech; Folha de São Paulo; Senses. 


\section{Palavras preliminares}

Falar sobre a contribuição da Linguística na compreensão da língua e seu processo de significação, é, sem dúvida, voltar aos caminhos percorridos por Saussure ao analisar a língua mediante seu caráter estrutural. Se hoje encontramos uma nova reconfiguração sobre o estudo dos elementos extralinguísticos, sobretudo em analisar o texto sincrônico, não podemos negar que tais contribuições foram possíveis através das aberturas deixadas pelo mestre genebrino na elaboração de propostas que se debruçam a Semiologia, bem como os estudos semióticos.

Dentre tantas ramificações da Linguística que ultrapassam os limites da estrutura do texto, mas partem dele para outros lugares possíveis, falamos dos estudos do discurso, mais especificamente da Análise do discurso francesa que trata de observar as diferentes semioses que constituem um texto. Mantemos, também, um diálogo com a Semiótica discursiva por considerar o jogo promovido na construção imagética do nosso corpus, que compreende dois anúncios publicitários do jornal Folha de São Paulo: um que traz a imagem de Hitler exibido em 1987 e outro anúncio com a imagem de Lula exibida em 2018.

Considerando que os sentidos não estão totalmente fora do texto, mas devem partir de uma materialidade, o artigo objetiva investigar, no discurso publicitário do jornal Folha de São Paulo, o diálogo entre dois sujeitos significativos na história política (inter)nacional: Lula e Hitler. Cada um, por seu turno, marca e desloca uma série de outros sentidos, seja dentro de uma positividade, seja dentro uma negatividade. Contudo, na reconfiguração traçada pelo discurso publicitário do periódico Folha, tais sujeitos aparecem difundidos. Aqui, nesta peça propagandista, as imagens se entrecruzam, promovem efeitos e transpassam o caráter da neutralidade e imparcialidade tão defendida e ao mesmo tempo questionada até no cenário jornalístico.

$\mathrm{O}$ artigo está sistematizado da seguinte forma: no primeiro momento adentramos pelos pressupostos teóricos da Análise do discurso francesa, na esteira de Foucault (2000; 2002; 2004; 2006) e Charaudeau (2006), dentre outros teóricos, e estabelecemos uma interlocução com os estudos da Semiótica greimasiana. No segundo tópico falamos um pouco sobre o que constitui o dizer midiático em que abordamos o processo de construção de sentido. E, por fim, no nosso último momento, faremos uma análise do 
corpus selecionado, identificando as estratégias articuladas no discurso jornalístico, mas revestido de um discurso político- publicitário.

\section{Nas tramas do discurso: percursos de sentido}

Surgida no final da década de sessenta, na França, época de profundas efervescências em vários campos da sociedade, sobretudo político, a Análise do discurso aparece como uma proposta de discutir os elementos ideológicos, a partir de materialidades diversas, seja um gesto, uma imagem, uma cor, um som e até mesmo o silêncio como produtor de sentido. Quando Michel Pêcheux (1938-1983) propôs, no auge das ideais difundidas no Partido Comunista Francês, reelaborar sua análise automática do discurso, na tentativa de identificar as engrenagens de uma maquinaria discursiva, não imaginava que os estudos do discurso pudessem contribuir na investigação de tantos gêneros discursivos em circulação na esfera social.

Ao lado de Pêcheux, aparece Michel Foucault (1926 - 1984) com sua análise sobre o sujeito e o atravessamento do poder. Inspirado no filósofo Nietsche, Foucault propõe uma análise arqueogenealógica. Defende, pois, que é necessário adentrar nas amarradas do discurso em busca de desvendar não o que o texto significa, mas como significa, pois "o discurso não é simplesmente aquilo que traduz as lutas ou os sistemas de dominação, mas aquilo por que, pelo que se luta, e poder do qual nos queremos apoderar." (FOUCAULT, 2000, p. 10).

Nos interessa, enquanto analistas do discurso, investigar: Como os elementos discursivos ocupam uma função disciplinar? O que há por traz de cada enunciado, de cada gesto, enfim, das verdades que foram se cristalizando ao longo do tempo? Tais questões dialogam com o fazer epistemológico de Foucault que está firmado nas seguintes preocupações teóricas: a) Como os saberes produzem isso que nós somos? Como as relações de poder interferem nisso que nós somos? $\mathrm{E}$ como se dão os processos de subjetivação? São aspectos basilares distribuídos ao longo do estudo de Foucault, em que ele transita em vários campos do saber, propondo rupturas e estabelecendo outras significações que inspiram os vários pesquisadores da atualidade não apenas no campo educacional.

Dentre tantos conceitos apresentados por Foucault é pertinente para nossa pesquisa, neste artigo, retomar a noção de arquivo, que seria: 
O que faz com que tantas coisas ditas por tantos homens, há tantos milênios, não tenham surgido apenas segundo as leis do pensamento, ou apenas segundo o jogo das circunstâncias, que não sejam simplesmente a sinalização, no nível das performances verbais (...) mas que tenham aparecido graças a todo um jogo de relações que caracterizam particularmente o nível discursivo. (FOUCAULT, 2004, p. 146).

A noção de arquivo problematizada na Análise do discurso nos permite identificar que os dizeres são uma retomada de dizeres outros, e, ainda, que o universo imagético, tão predominante nos dias atuais, funciona como terreno fértil para a proliferação de "verdades" que devem ser questionadas. Nenhum signo tem um sentido único, e isto já é defendido desde os primórdios do próprio método de investigação científica de Saussure. Como afirma Foucault:

Nenhum signo surge, nenhuma fala se enuncia, nenhuma palavra ou nenhuma proposição jamais visa a algum conteúdo senão pelo jogo de uma representação que se põe à distância de si, se desdobra e se reflete numa outra representação que lhe é equivalente." (FOUCAULT, 2002, p.108). (grifos nossos).

Deste modo, tudo que é proferido, seja em qualquer modalidade, seja na linguagem verbal ou não-verbal, sempre compreende um jogo de uma representação, entre o que seria a "verdade", algo que não passa de uma trama discursiva. Assim, estudar o percurso de sentido constituído no discurso, que é manifestado no texto, é entender a dinâmica da linguagem, ou seja, a língua em ação.

E no diálogo proposto com a Semiótica, mais especificamente na vertente greimasiana, nos interessa aqui a análise dos sistemas semióticos da mídia, pois "a semiótica, como teoria da significação, preocupa-se com as condições de "apreensão e produção do sentido". (GREIMAS e COURTÉS, 2011, p.455). Os elementos semióticos passam, assim, por três percursos: estrutura profunda, estrutura narrativa, estrutura discursiva.

Nos deteremos, como melhor promoção deste diálogo com a AD francesa, a estrutura discursiva, que nos permite analisar como os elementos se organizam e promovem significações. É no nível discursivo o mais superficial do percurso e também o mais complexo semanticamente. No discurso publicitário, por exemplo, há um sujeito que age sobre outro sujeito. Esta ação se dá pela manipulação, pelo convencimento, que seria a base de todo processo comunicativo, portanto, discursivo. 
É necessário percorrer o caminho trilhado pelos sujeitos em busca de entender como os elementos se ajustam para promover efeitos de sentido. Há uma ordem, uma organização que possibilitam a identificação de outros elementos nem sempre perceptíveis apenas com um breve passar de olhos. As teorias do discurso contribuem para que entendamos que os textos não são tão somente artefatos comunicacionais, ou aglomerados de frases. Mas dispositivos discursivos, campo de subjetividades, espaços de significações.

\section{O discurso midiático como um terreno de subjetividades}

Nunca se falou tanto em mídia ou em manipulação da mídia como nos últimos tempos. Isto porque a mídia funciona como um dispositivo de controle, capaz de influenciar em decisões nos mais diferentes setores da sociedade. Sobre este aspecto Charaudeau faz a seguinte observação:

Na verdade, o cidadão nunca tem acesso ao acontecimento bruto, ele sempre entra em contato com um acontecimento filtrado pela mídia. Assim, ora acontecimento bruto e acontecimento veiculado pela mídia se confundem, ora um prepondera sobre o outro, criando um círculo vicioso, como demonstra o tratamento midiático de alguns casos. (CHARAUDEAU, 2006, p. 256).

A problematização articulada por Charaudeau (2006) dialoga com as afirmações de Foucault, conforme vimos, ao defender que os signos se desdobram, se refletem mediante um jogo de representação. Deste modo, é fundamental entender que na mídia, há uma fabricação da verdade, que pode resultar em aspectos positivos ou negativos dependendo em quem se quer atingir, pois "o que os textos da mídia oferecem não é a realidade, mas uma construção que permite ao leitor produzir formas simbólicas de representação da sua relação com a realidade concreta." (GREGOLIN, 2003, p.97).

Ancorados no discurso da credibilidade e imparcialidade das informações, aspectos já revistos nos próprios centros de formação de jornalistas, entendemos que nenhuma palavra, nenhum signo é totalmente desprovido de ideologia. Numa era de plena revolução tecnológica, típica deste século XXI, o discurso midiático aparece para o público, emoldurado de técnicas tipográficas - dispositivos de controle que se aproximam do fazer cinematográfico. A imagem, ou seja, os efeitos aprimorados pelo fotojornalismo aliados aos textos verbais, contribuem para ditar o ritmo do (re)dizer, e, 
assim, os enunciados produzidos pela mídia, atuam como verdades únicas que, a rigor, disciplinam o olhar dos leitores em seus mais diversos segmentos sociais.

Mediante o poder de influência dos textos midiáticos, faz-se mais do que urgente e necessário discutir e analisar os efeitos de sentido neles constituídos, por nos atingir de formas diversas, através de uma infinidade de recursos, técnicas e mecanismos disciplinares. No campo da educação, utilizar a mídia, o texto jornalístico, é uma prescrição regulamentar firmada nos documentos oficiais e no mais recente que é a BNCC (Base Nacional Comum Curricular):

(EF69LP04) Identificar e analisar os efeitos de sentido que fortalecem a persuasão nos textos publicitários, relacionando estratégias de persuasão e apelo ao consumo com os recursos linguístico-discursivos utilizados, como imagens, tempo verbal, jogos de palavras, figuras de linguagem etc., com vistas a fomentar práticas de consumo conscientes. (BRASIL, BNCC, 2018, p. 139).

Os pressupostos das teorias discursivas nos fornecem subsídios para ver e entrever que é fundamental trabalhar os efeitos de sentido que engendram os textos em circulam na esfera midiática, cujo objetivo é formar opinião, é conquistar mentes e corações dos sujeitos. Manter informados nossos alunos e discutir os fatos da atualidade constituem algumas das premissas que devem constar nas agendas e currículos e programas escolares.

Trabalhar textos da atualidade, conforme determina a BNCC, fortalece as estruturas democráticas e dimensionam o ensino, primando pela pluralidade da leitura e nos distanciando, assim, das metodologias fossilizadas pautadas tão somente em decorar nomenclaturas estritamente gramaticais sem qualquer reflexão crítica. São estas algumas contribuições fundamentadas na seguinte análise que nos propiciam um olhar mais apurado para os efeitos de sentido presentes no discurso publicitário da Folha de São Paulo em dois momentos distintos - década de 1980 e 2018).

\section{No discurso publicitário da Folha de São Paulo: o diálogo das imagens}

O jornal Folha de São Paulo atua no Brasil desde 1921 e tem uma tiragem de 332.415 exemplares. Em 2018 a Folha reformulou o seu Manual de Redação fundamentado no slogan: "Aberta à opiniões. Fechada com os fatos" amplamente divulgado em várias plataformas midiáticas. A primeira peça que iremos analisar foi veiculada no ano de 1987. O filme "Hitler", da agência W/Brasil, ganhou inúmeros 
prêmios, inclusive o Leão de Ouro no Festival de Cannes, o mais importante de todos. É um dos dois únicos comerciais brasileiros e ibero-americanos na lista dos cem melhores de todos os tempos. Com duração de 1:02, as imagens vão surgindo com pontinhos pretos na tela, acompanhados de um narrador e uma música de suspense, vejamos a sequência:
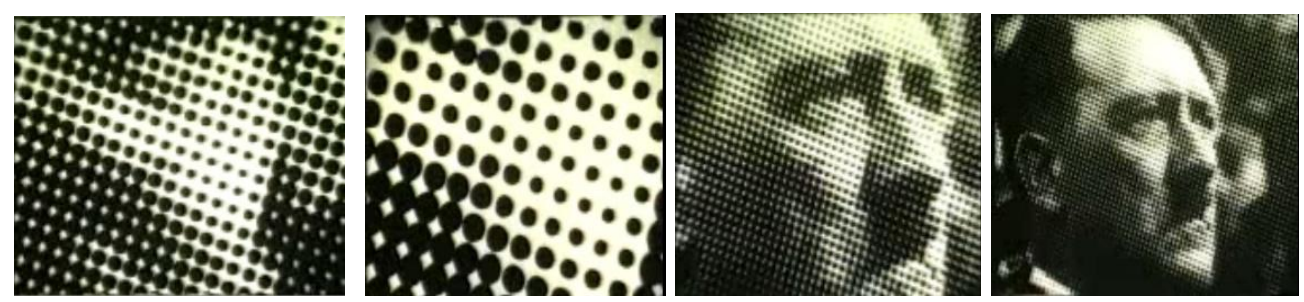

IMAGEM 1: Hitler - anúncio da Folha de São Paulo

Fonte: https://www.youtube.com/watch?v=ly7g5frxg-I

A peça foi veiculada na TV e aparece mediante semioses (música de fundo, imagens, jogo de cores) que vão acompanhando o ritmo da música com um tom de suspense e no final a imagem com o rosto de Hitler aparece em sua totalidade e vai dialogando sincronicamente com o seguinte texto:

\begin{abstract}
Este homem pegou uma nação destruída. Recuperou sua economia e devolveu o orgulho ao povo. Em seus quatro primeiros anos de governo, o número de desempregados caiu de seis milhões para novecentas mil pessoas. Este homem fez o produto interno bruto crescer cento e dois por cento e a renda per capta dobrar. Aumentou os lucros das empresas de cento e setenta e cinco milhões para cinco bilhões de marcos e reduziu uma hiperinflação a no máximo vinte e cinco por cento ao ano. Este homem adorava música e pintura. E quando jovem, imaginava seguir a carreira de artista. É possível contar um monte de mentiras dizendo só a verdade. Por isso, é preciso tomar muito cuidado com a informação do jornal que você recebe. Folha de São Paulo: o jornal que mais se compra e que nunca se vende. (FOLHA DE SÃO PAULO, 1987).
\end{abstract}

Os enunciados contidos na mensagem são aditados para apresentar a biografia de uma das figuras mais abomináveis do século XXI. O texto abrange várias áreas da vida desta pessoa, tais como: educação, política e economia. Após elucidar uma sequência de signos que qualificam este sujeito ainda sem face, eis que ressurge a verdadeiro rosto de alguém que ainda estava no anonimato: Adolf Hitler - um sujeito responsável pela morte de mais de 5 (cinco) milhões de pessoas na justificativa de construir uma nova sociedade, uma raça pura e legítima. 
Os efeitos de sentido instaurados pela Folha, neste texto, discursivizam que o periódico é sério, confiável, e neste diálogo estabelecido com o leitor, emoldurado nas estratégias publicitárias, procura alertar o leitor para comprovar os fatos e questionar o teor ideológico publicado em outros veículos de informação. Certamente se tal peça publicitária fosse veiculada nos dias atuais, em 2019, o cerne da temática estaria direcionado para o que se entende hoje por Fake News. Mas na década de 1980, antes da promulgação da Carta Magna do Brasil - a Constituição - início do processo de redemocratização do país, ainda havia espaço para desconfianças. Daí, a necessidade de problematizar as "verdades" publicadas em outros meios, e voltar-se para os jornais considerados de tradição no seio da sociedade brasileira como a Folha, por exemplo.

A peça publicitária com duração de 1:02 vai, assim, guiando o leitor e ditando o ritmo do (re)dizer com um discurso emoldurado em um jogo de semioses, cores, imagens em que predominam apenas duas cores para construir um efeito de neutralidade e imparcialidade, além do caráter de retrocesso, o passado assombroso que ainda luta em reaparecer e se manter vivo.

Deste modo, Em busca de se subjetivar perante o público, enquanto jornal sério, de credibilidade (conforme regem os princípios do jornalismo), a Folha promove uma "volta do acontecimento" ao criar, através dos recursos tecnológicos, neste universo semiótico (utilização de pontos na tela, predominância das cores preta e branca, música de suspense e voz do narrador), um efeito de realidade com a imagem de Hitler. Joga com o passado e (re)conta uma história do tempo presente.

A segunda peça publicitária veiculada também pela Folha de São Paulo compreende um anúncio de trinta segundos que foi exibido em 2018, antes das eleições presidenciais, especialmente pela internet e TV fechada, sobretudo nos intervalos da Globonews e Bandnews. O discurso é constituído por emoticons advindos das redes sociais que promovem uma interdiscursividade com a diversidade de reações das pessoas, frente aos fatos polêmicos que aqueceram o cenário político entre 2018 e início de 2019.

Contudo, a imagem que é revelada logo depois, como plano de fundo, é o rosto, em preto e branco, do ex-presidente Lula que contrasta com as cores das "carinhas" das redes sociais. O ritmo da música é bem acelerado e se reveste de uma atualidade, uma 
linguagem mais contemporânea e atrativa mais voltada para o público jovem. Vejamos a sequência:

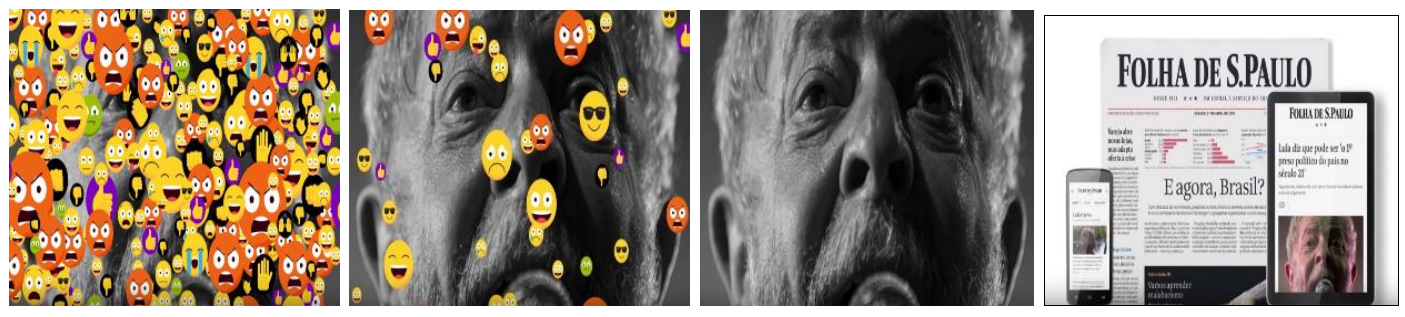

IMAGEM 2: Lula - anúncio da Folha de São Paulo

Fonte: https://www.youtube.com/watch?v=dr4w5mlIKgs

A sequência de imagens é acompanhada pelo seguinte texto:

Tem gente que fala na Folha que ele comandou um grande esquema de corrupção no país. Que ele é o maior bandido da República. E que um condenado não pode concorrer à eleição. Também tem gente que fala na Folha que ele foi de longe o melhor presidente do Brasil. Que ele é inocente. E que a eleição sem ele é fraude. Você lê todo tipo de opinião na Folha. Mas nas reportagens só publicamos aquilo que aconteceu. Folha: aberta a opiniões. Fechada com os fatos. (FOLHA DE SÃO PAULO, 2018).

O anúncio segue o conceito "Aberta a opiniões. Fechada com os fatos" como uma retomada do lançamento do novo manual da Folha. Segundo a agência África a peça afirma a essência editorial do veículo, que se compromete sempre com o fato, abrindo espaço para as mais diversas opiniões e correntes de pensamento. Uma forma de reafirmar a neutralidade e credibilidade dos fatos como dissemos no item anterior.

Mediante os percursos discursivos da memória, observamos que a Folha recupera, após 31 anos, sua peça premiada, em que trazia a figura de Hitler, para moldar a imagem de Lula que estava pleiteando sua candidatura à presidência da República. Embora (re)crie um discurso que respeita as opiniões, o que prevalece é o seu filtro, ou seja, construir uma negatividade de Lula perante o público - o que ela considera ser "Fechada com os fatos".

As duas peças publicitárias, a rigor, atendem interesses capitalistas, pois não podemos ignorar que as empresas de informação só funcionam porque são sustentadas por anunciantes. Contudo, tal dependência acaba gerando consequências negativas que comprometem, significativamente a credibilidade das informações, sobretudo quando são tratados termas políticos -um aspecto cada vez mais polemizado por especialistas do campo da linguagem, pois: 
Num mundo cada vez mais pilotado por empresas colossais que obedecem à lei do business e exclusivamente à lógica comercial, e onde tantos governos parecem escapar sofrivelmente às mutações em curso, como ter certeza de que não somos manipulados pela mídia? (RAMONET, 1999, p.29).

Como no anúncio anterior veiculado em 1987, o texto produzido em 2018 reaparece com uma nova roupagem dialogando, assim, com o discurso da atualidade através de diversos efeitos tecnológicos. Diferentemente da peça que projeta Hitler, em que se observa apenas duas cores, o discurso articulado agora em 2018, projetando a imagem de Lula, vem com uma explosão de cores fortes na tentativa de promover uma certa desordem, talvez para dialogar com a origem do ex-presidente que advém de classes menos favorecidas.

Tanto a propaganda de 1987 como a de 2018, promovem uma interdiscursividade com o passado. Embora veiculadas em épocas diferentes, trazem imagens dos líderes, Hitler e Lula, ao instaurar jogos de verdade e mentira, entre o que seria fato e o que seria fake.

A utilização das imagens e seus recursos interativos com o leitor/internauta, procuram manter uma relação de proximidade para formar opinião acerca dos dizeres historicamente construídos. Devemos, assim, tratar o texto, mapeando seu percurso gerativo de sentido. O sentido está no diálogo entre os dizeres verbais e não verbais, no jogo de representação entre o presente recente e o passado distante. Mas no momento que a temporalidade é acionada, ressurgem outros efeitos de sentido e são cristalizadas verdades capazes de atuar diretamente no imaginário social.

\section{Considerações finais:}

Surgido em 1921 e se subjetivando como "Um jornal a serviço do Brasil, Folha sempre cultivou raízes profundas na história do Brasil". Ao trazer a imagem de Lula em um momento de pré-candidatura presidencial em 2018, a Folha recupera Hitler, um dos maiores genocidas da história da humanidade, para produzir um discurso negativo e formar uma opinião sobre o atual líder da esquerda do Brasil - Lula.

Os dois anúncios, mesmo publicados em épocas distintas, materializam formas de poder e apresentam uma sofisticação no texto, abusam de efeitos tecnológicos, bem como revelam um cuidado com a escolha dos enunciados, com as pausas e formas de utilizar os recursos linguísticos para vender um produto - a informação. 
Embora nos dias atuais (2019) a Folha tenha estabelecido uma parceria com o The Intercept Brasil, no projeto "Vaza Jato", em denunciar possíveis crimes envolvendo os procuradores da força-tarefa, não devemos esquecer que a conduta da Folha dialoga com uma política neoliberalista, pois sempre prestou assessoria aos interesses empresariais. A Folha se funde as duas imagens para promover efeitos de uma negatividade perante um governo de esquerda, e, com tal dispositivo discursivo, legitima a imprensa oligárquica se brasileira em atender aos interesses comerciais que a sustentam.

\section{Referências bibliográficas:}

BRASIL. Base Nacional Comum Curricular: Educação é a base. Ministério da Educação: 2018.

CHARAUDEAU, Patrick. Discurso das mídias. São Paulo: Contexto, 2006.

FOUCAULT, Michel. A ordem do discurso. 6ed. São Paulo: Brasil, 2000.

As palavras e as coisas. 8 ed. São Paulo: Marins Fontes, 2002.

Arqueologia do saber. Rio de Janeiro: Forense Universitária, 2004.

GREIMAS, Algirdas e COURTÉS, Joseph. Dicionário de semiótica. São Paulo: Contexto, 2011.

GREGOLIN, Maria do Rosário. Discurso e mídia: a cultura do espetáculo. São Paulo: Claraluz, 2003.

HERNANDES, Nilton. A mídia e seus truques: o que o jornal, revista, TV, rádio e internet fazem para captar e manter a atenção do público. São Paulo: Contexto, 2006.

RAMONET, Ignácio. A tirania da comunicação. Petrópolis: Vozes, 1999.

RASTIER, François. Greimas e a linguística. Tradução de Maria de Fátima Barbosa de Mesquita Batista. Acta Semiotica et Lingvistica. Vol 22 - Ano 41 - No 2, Julho a Dezembro de 2017: p.112-129. Disponível em:

https://periodicos.ufpb.br/index.php/actas/article/view/38120/19353 Acesso 10/08/2019

\section{Sites consultados:}

Anúncio da Folha de 1987.

Disponível em: https://www.youtube.com/watch?v=ly7g5frxg-I. Acesso em 10 de Agosto de 2019.

Anúncio da Folha em 2018.

Disponível em: https://www.youtube.com/watch?v=dr4w5mlIKgs. Acesso em $10 \mathrm{de}$ Agosto de 2019. 